Vol. 3, No. 2, June 2021 e-ISSN: 2656-4882 p-ISSN: 2656-5935

\title{
Pieces Framework for Analysis of User Saticfaction Internet of Things-Based Devices
}

\author{
Nestiara Lidya Kakihary ${ }^{1}$ \\ ${ }^{1}$ Fakultas Teknologi Informasi, Universitas Kristen Satya Wacana, Salatiga, Indonesia \\ Email: $\underline{\text { 682017110@uksw.edu }}$
}

\begin{abstract}
Abstrack
Internet of Things is a concept where internet connectivity can exchange information with one another with the existing devices around it. IoT can help humans in their daily activities. In general, Internet of Things-based devices can perform controlling and scheduling. In this research, an analysis of the level of power saving using smart lamp and smart plug devices based on the Internet of Things will be carried out. The analysis carried out in this study used the PIECES method which is a framework that can classify a problem, opportunity, and directives. Research on the efficiency of electricity savings based on IoT devices will be supported using devices and applications from Bardi Smart Home. In addition to the PIECES method, this analysis and research is supported by using the IoT framework: Conceptual Framework, and will be supported by IoT-based devices from Bardi Smart Home.
\end{abstract}

Keywords : Internet of things (IOT), IoT Framework, Big Data, PIECES Framework, Bardi smart home

\section{PENDAHULUAN}

Tingkat penggunaan listrik semakin meningkat setiap tahun. Berdasarkan data dari Kementerian ESDM, pada tahun 2015 sampai dengan 2020 penggunaan daya listrik semakin meningkat. Peningkatan ini sejalan dengan rasio elektrifikasi yang juga menunjukkan kenaikan. Banyak orang membutuhkan aliran listrik untuk menunjang aktivitas sehari-hari. Pemantauan dan pengontrollan daya listrik perlu dilakukan untuk meminimalisir pemakaian listrik yang berlebihan agar daya listrik dapat digunakan secara efisien.

Dalam membantu penghematan daya listrik, dibutuhkan suatu alat ataupun perangkat yang menunjang untuk menjadi solusi dalam penghematan daya listrik. Seperti yang diketahui IoT dapat menyambungkan alat-alat fisik seperti lampu, televisi, kulkas bahkan pintu rumah terhubung ke Internet secara terus-menerus dan dapat dikendalikan pada jarak jauh melalui smartphone pengguna yang terhubung dengan jaringan internet. Internet of Things merupakan solusi terbaik 
Vol. 3, No. 2, June 2021

p-ISSN: 2656-5935 http://journal-isi.org/index.php/isi e-ISSN: $2656-4882$

yang menawarkan pemantauan dan pengontrollan perangkat untuk penghematan daya dari tempat dan jarak yang berbeda.

Perangkat yang digunakan dalam penelitian ini adalah smart lamp dan smart plug dari Bardi Smart Home. Big Data dan Internet of Things (IoT) memiliki keterkaitan yang sangat erat. IoT mengumpulkan, menganalisis, berbagi dan mengirim data secara real time, menuntut beban yang lebih besar pada kemampuan big data. Data hasil penjaringan IoT mendorong teknologi penyimpanan data secara lebih modern dan efisien. PIECES Framework dipakai untuk mengklasifikasikan suatu problem, opportunities, dan directives yang terdapat pada bagian scope definition analisis dan perancangan sistem. PIECES Framework dalam analisis dan penelitian ini dipakai untuk mengukur tingkat efektifitas perangkat maupun aplikasi Bardi Smart Home dan yang paling utama mengukur tingkat kepuasan pengguna perangkat maupun aplikasi Bardi Smart Home dalam membantu aktivitas sehari-hari, contohnya dalam manajemen penggunaan daya listrik yang teratur dan kemudahan dalam melakukan pengontrollan jarak jauh yang lebih praktis dan mudah.

\section{LANDASAN TEORI}

\subsection{Tingkat Penggunaan Listrik di Indonesia}

Sumber data dari Kementerian Energi dan Sumber Daya Mineral Republik Indonesia, penggunaan listrik meningkat selama 5 tahun terakhir. Dari data tersebut konsumsi listrik nasional terus mengalami peningkatan. Pada 2015 konsumsinya baru 910 kilowat jam $(\mathrm{kWh})$ per kapita. Kemudian meningkat menjadi $1.084 \mathrm{kWh} /$ kapita pada 2019. Peningkatan ini sejalan dengan rasio elektrifikasi yang juga menunjukkan kenaikan. Rasionya dari 84,35\% pada 2014 menjadi 98,89\% pada 2019. Akses listrik di hampir menjangkau seluruh wilayah Indonesia pun telah mencapai lebih dari 95\%, hanya Nusa Tenggara Timur yang masih 85\% dan Maluku 92\%. Lalu, Kalimantan Tengah, Sulawesi Tenggara, dan Papua juga masih 94\%.

\subsection{Pengertian IoT}

Internet of Things (IoT) adalah konsep dimana konektifitas internet dapat bertukar informasi satu sama lainnya dengan benda yang ada disekelilingnya. Pengertian Internet of Things menurut Kevin Ashton dalam e-book yang berjudul "Making Sense of Iot": "Pengertian Internet of Things' adalah sensor-sensor yang terhubung ke internet dan berperilaku seperti internet dengan membuat koneksi-koneksi terbuka setiap saat, serta berbagi data secara bebas dan memungkinkan aplikasiaplikasi yang tidak terduga, sehingga komputer dapat memahami dunia sekitar mereka menjadi bagian dari kehidupan manusia". Istilah Internet of Things disarankan oleh Kevin Ashton tahun 1999 dan mulai terkenal melalui Auto-ID Center di Massachusetts Institute of Technology (MIT). Io'T dapat melakukan 
Vol. 3, No. 2, June 2021

p-ISSN: 2656-5935 http://journal-isi.org/index.php/isi e-ISSN: $2656-4882$

pemantauan dan pengontrollan menggunakan gadget yang terhubung dengan jaringan internet dalam jarak dan waktu yang berbeda. Komponen pembentuk IoT yaitu : Kecerdasan Buatan (Artificial Intelegent), Konektivitas, Server, Keterlibatan Aktif (Active Engagement), dan Perangkat berukuran kecil.

\subsection{PIECES Framework}

PIECES Framework adalah kerangka yang dipakai untuk mengklasifikasikan suatu problem, opportunities, dan directives yang terdapat pada bagian scope definition analisis dan perancangan sistem. Menurut (Whitten \& Bentley, 2007, p.77) PIECES Framework merupakan sebuah framework yang berisi kategori-kategori pengklasifikasian masalah dan membuat pemecahan dari masalah tersebut. Kerangka PIECES ini dapat digunakan untuk pengembangan sistem. Dalam PIECES terdapat 6 elemen analisis yaitu sebagai berikut Performance (Kinerja), Information and Data (Informasi dan Data), Economics (Ekonomi), Control and Security (Kontrol dan Keamanan), Efficiency (Efisiensi), Service (Layanan).

\subsection{Big Data}

Istilah Big Data mengacu pada data yang besar, cepat, dan kompleks sehingga sulit ataupun tidak mungkin untuk diproses dengan menggunakan metode yang lama atau dengan kata lain tradisional. Tindakan mengakses dan menyimpan sejumlah besar informasi untuk analitik telah ada sejak lama. Konsep big data mendapatkan momentum di awal tahun 2000-an ketika analis industri Doug Laney mengartikulasikan definisi big data yang sekarang menjadi 3 yaitu : Volume (ukuran), Velocity (kecepatan), dan Variety (variasi).

\subsection{Aplikasi dan Perangkat Bardi Smart Home}

Aplikasi Smart Home adalah aplikasi yang menunjang aktivitas penggunaan perangkat berbasis IoT. Aplikasi Smart Home biasanya digunakan untuk proses konektivitas perangkat, penjadwalan perangkat, dan pengontrollan perangkat menggunakan smartphone. Bardi smart home mendukung pemantauan, pengontrollan, dan penjadwalan berbasis Internet of Things. Perangkat yang paling sering digunakan adalah smart lamp dan smart plug. Smart lamp sendiri merupakan barang fisik berupa lampu yang dipasang modul wireless dan terhubung dengan jaringan internet dan platform clouds. Yang membuat smart lamp berbeda dari lampu biasa adalah fungsi pengontrollannya yang sangat praktis karena hanya menggunakan gadget yang terhubung dengan internet sebagai alat untuk mengontrol walaupun dari jarak dan waktu yang berbeda. Smart Plug tidak jauh berbeda dengan smart lamp, hanya ada perbedaan bentuk fisik dan kegunaan. Bentuk fisik smart plug sama dengan plug/soket pada umumnya, yang menjadi perbedaan kecil adalah adanya tombol khusus pada smart plug yang berfungsi 
Vol. 3, No. 2, June 2021

p-ISSN: 2656-5935 http://journal-isi.org/index.php/isi e-ISSN: 2656-4882

untuk konektivitas perangkat dengan gadget. Smart plug juga memiliki fungsi pengontrollan yang sama dengan smart lamp.

\section{METODE PENELITIAN}

\subsection{Variabel PIECES Framework}

Tabel 1. Variabel PIECES

\begin{tabular}{|c|l|c|}
\hline $\begin{array}{c}\text { No } \\
.\end{array}$ & \multicolumn{1}{|c|}{ Variabel } & Jumlah Pertanyaan \\
\hline 1. & Performance & 3 \\
\hline 2. & Information and Data & 2 \\
\hline 3. & Economics & 2 \\
\hline 4. & Control and Security & 3 \\
\hline 5. & Efficiency & 3 \\
\hline 6. & Service & 2 \\
\hline
\end{tabular}

Skala Tingkat Kebaikan dan Skala Tingkat Kepuasan

\begin{tabular}{|c|c|}
\hline Pilihan Jawaban & Skor \\
\hline Sangat Baik & 4 \\
\hline Baik & 3 \\
\hline Cukup Baik & 2 \\
\hline Tidak Baik & 1 \\
\hline
\end{tabular}

\begin{tabular}{|c|c|}
\hline Pilihan Jawaban & Skor \\
\hline Sangat Puas & 4 \\
\hline Puas & 3 \\
\hline Cukup Puas & 2 \\
\hline Tidak Puas & 1 \\
\hline
\end{tabular}

Instrumen pengumpulan data yang di gunakan berupa pertanyaan-pertanyaan yang telah disusun berdasarkan perumusan metode PIECES. Penjabaran metode PIECES adalah sebagai berikut : Performance (P) dapat dilihat dan diukur melalui 2 elemen yaitu throughput dan respon time contohnya masalah kinerja dan waktu tanggap atau respon antar perangkat dan aplikasi. Information and Data (I) dapat dinilai berdasarkan keakuratan informasi, kerelevanan informasi, dan ketepat waktuan informasi yang diberikan kepada pengguna. Economics (E) dilihat dari besaran biaya, Control and Security (C) mencakup control dan keamanan yang lemah, data yang tersimpan tidak konsisten, data dapat diakses orang yang tidak berwenang ataupun terjadi redudansi. Kemudian hal lainnya yaitu pelanggaran panduan atau privacy, dan terjadi error pada pemrosesan data antar perangkat dan aplikasi. Efficiency (E) dapat dilihat dan diukur apabila perangkat sudah diimplementasikan, kemudian proses pengukuran tingkat efisiensi dalam hal ini kehematan daya listrik dapat dilakukan untuk mendaptkan besaran tingkat kehematan setelah pengimplementasian perangkat tersebut. Service (S) merupakan kriteria penilaian kualitas, contohnya penampilan data yang tidak akurat, ssstem yang sulit digunakan, layanan yang diberikan tidak efektif. Pengumpulan data dilakukan dengan cara pengujian penerapan perangkat pada 10 responden selama 
Vol. 3, No. 2, June 2021

p-ISSN: 2656-5935 http://journal-isi.org/index.php/isi

e-ISSN: 2656-4882

7 hari dan dilakukan pembagian kuesioner untuk 10 orang responden yang telah melakukan pengujian perangkat selama 7 hari. 7 hari dinilai sudah cukup efisien untuk dilakukan proses uji coba perangkat kepada responden karena dalam 7 hari responden aktif melakukan aktivitas yang melibatkan alat elektronik yang terhubung dengan daya listrik. Penelitian ini dilakukan dengan bantuan 10 orang responden dengan 2 jenis perangkat berbeda yaitu Smart Plug dan Smart Lamp. Penggunaan smart plug terhubung dengan 4 perangkat elektronik yang berbeda. Untuk smart plug sendiri, masing-masing jenis alat elektronik digunakan oleh 2 orang di tempat yang berbeda agar nantinya dilakukan perbandingan durasi aktivitas penggunaan dan jumlah daya listrik yang terpakai. Pembagian untuk penggunaan Smart Plug ini sebagai berikut : 2 orang terhubung dengan dispenser, 2 orang terhubung dengan televise, 2 orang terhubung dengan AC, dan 2 orang terhubung dengan charger handphone. Responden nantinya dapat mengevaluasi perangkat yang digunakan. Pemilihan alat eletronik tersebut untuk dilakukan uji coba dengan terhubung ke perangkat Smart Plug mengacu pada tingginya tingkat kebutuhan manusia pada alat eletronik diatas dalam kehidupan sehari-hari. Penggunaan Smart Lamp dilakukan oleh 2 orang di tempat berbeda untuk nantinya dibandingkan serta dilakukan evaluasi terhadap perangkat yang digunakan.

\section{HASIL DAN PEMBAHASAN}

\subsection{IoT: Conceptual Framework}

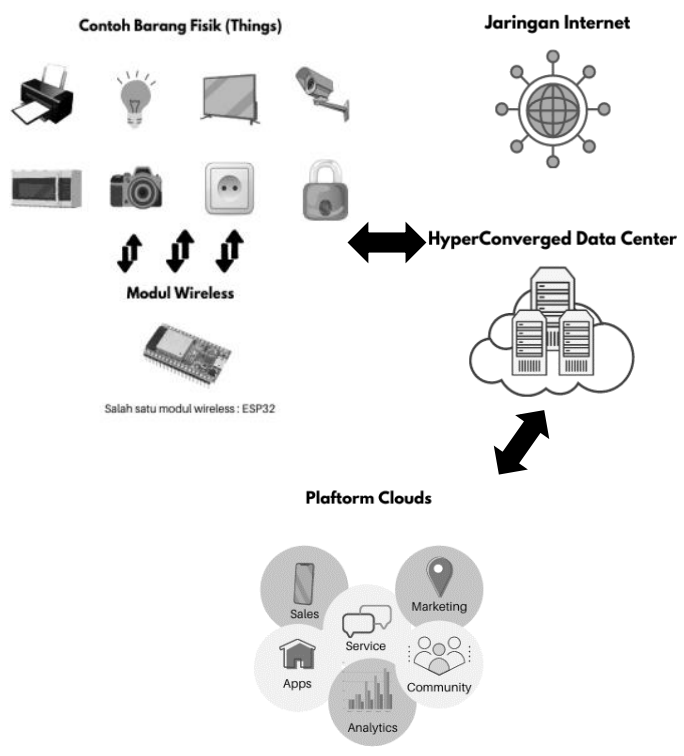

Gambar 1. Konseptual Framework 
Konsep IoT ini sebetulnya cukup sederhana dengan cara kerja mengacu pada 3 elemen utama pada arsitektur Io $T$, seperti: Barang fisik yang dapat digunakan bisa berupa printer, lampu, smart tv, cctv, microwave, kamera, smart plug, dan smart lock yang nantinya dilengkapi dengan modul wireless ESP32 . Perangkat seperti gadget juga dibutuhkan untuk membantu menunjang pengoperasian Internet of Things, perangkat tersebut harus bisa terhubung dengan jaringan internet melalui modem maupun router. Fungsi Cloud Data Center sangat penting karena semua data tentang akun, jaringan wifi, lalu lintas penggunaan aplikasi, aktivitas penggunaan antar perangkat dan aplikasi disimpan di dalam Cloud Data Center.

Seluruh penggunaan barang yang terhubung ke jaringan internet akan menyimpan data, data tersebut terkumpul sebagai Big Data yang kemudian dapat di olah untuk di analisa baik oleh pemerintah, perusahaan, maupun negara asing untuk kemudian dapat dimanfaatkan untuk kepentingan masing-masing. Big Data sendiri adalah beberapa atau kumpulan proses yang terdiri dari volume data dalam jumlah yang besar, baik itu terstruktur maupun tidak. Secara langsung, big data dapat membantu proses bisnis. Big data sangat berperan penting khususnya dalam membantu pembuatan maupun pengembangan perangkat cerdas.

\subsection{Elemen-elemen untuk mebentuk atau menciptakan IoT}

Ada beberapa elemen untuk membentuk atau menciptakan IoT, yaitu:

- Kecerdasan Buatan (Artificial Intelligence/AI) - IoT dapat membuat semua perangkat atau bahan fisik yang ada menjadi "Smart". Dengan kata lain IoT bisa meningkatkan semua bagian dalam kehidupan dengan pengembangan teknologi yang bersumber pada $A I$. Jadi, pengembangan teknologi yang ada dilakukan dengan pengumpulan data, algoritma kecerdasan buatan, dan jaringan. Misalkan barang elektronik yang tergolong sederhana yaitu AC, dengan bantuan kecerdasan buatan IoT maka AC tersebut dapat di control dari jarak jauh dan AC tersebut dapat menstabilkan suhu ruangan secara otomatis agar tidak terlalu panas ataupun dingin.

- Konektivitas - Dalam IoT, ada kemungkinan untuk membuka, menciptakan, maupun membangun jaringan yang baru, dan jaringan khusus IoT. Dalam hal ini, jaringan ini tidak terikat dengan sumber utamanya. Jaringan tidak perlu memiliki skala yang besar dan memakan dana yang banyak, jaringan bisa tersedia pada skala yang lebih kecil, praktis, dan lebih murah. IoT bisa menciptakan ataupun membuat jaringan tersebut diantara perangkat sistem.

- Sensor - Sensor ini merupakan pembeda yang membuatIoT istimewa dibanding mesin canggih lainnya. Sensor dapat mendeskripsikan sebuah instrumen, yang dapat menganti $I o T$ dari jaringan standar dan cenderung pasif dalam perangkat, hingga menjadi suatu sistem aktif yang mampu diintegrasikan ke dalam aktivitas sehari-hari.

- Keterlibatan Aktif (Active Engagement) - Engangement yang sering diimplementasikan teknologi pada umumnya termasuk pasif. IoT 
Vol. 3, No. 2, June 2021

p-ISSN: 2656-5935 http://journal-isi.org/index.php/isi

e-ISSN: $2656-4882$

menghadirkan sudut pandang yang baru bagi konten aktif, produk, dan keterlibatan layanan.

- Perangkat Berukuran Kecil - Sesuai yang diperkirakan para pakar teknologi perangkat menjadi semakin kecil, semakin murah, dan lebih kuat seiring berkembangnya zaman. IoT memanfaatkan perangkat-perangkat kecil yang dibuat khusus agar dapat menghasilkan ketepatan, skalabilitas, dan fleksibilitas yang baik.

\subsection{PIECES Framework}

Berikut ini hasil pengisian kuesioner menggunakan kerangka pieces yang melibatkan 10 orang responden yang melakukan pengujian alat untuk mendapatkan hasil penelitan.

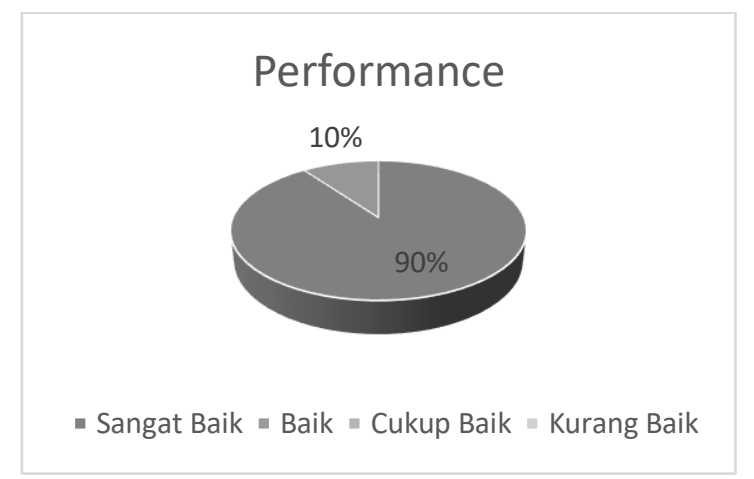

Gambar 2. Performace

Hasil penelitian terhadap 10 orang responden, 9 dari 10 menilai bahwa performa perangkat Bardi sudah sangat baik dalam membantu pemantauan, pengontrollan dan penjadwalan perangkat. 1 orang lainnya menilai bahwa performa yang diberikan kurang baik jika jaringan wifi tidak stabil.

\section{Information \& Data}

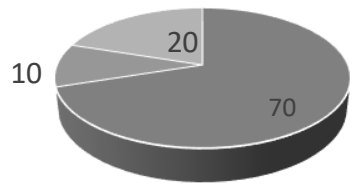

- Sangat Baik - Baik - Cukup Baik - Kurang Baik

Gambar 3. Informasi dan Data 
Vol. 3, No. 2, June 2021

p-ISSN: 2656-5935 http://journal-isi.org/index.php/isi

e-ISSN: 2656-4882

Hasil penelitian terhadap 10 orang responden, 7 dari 10 orang menilai bahwa informasi dan data yang diberikan oleh Bardi, mulai dari guide book, tahapan penginstallan pada aplikasi, sampai dengan informasi dan data yang ditampilkan pada aplikasi sudah cukup baik. 1 dari 10 orang responden menilai baik namun ada kekurangan dengan alasan beberapa tahapan yang tertera pada guide book kurang jelas. Sedangkan 2 responden lainnya menilai bahwa untuk perangkat smart lamp sudah cukup baik dalam hal pengontrollan dan penjadwalan tetapi kekurangannya yaitu tidak ada informasi mengenai jumlah penggunaan daya listrik.

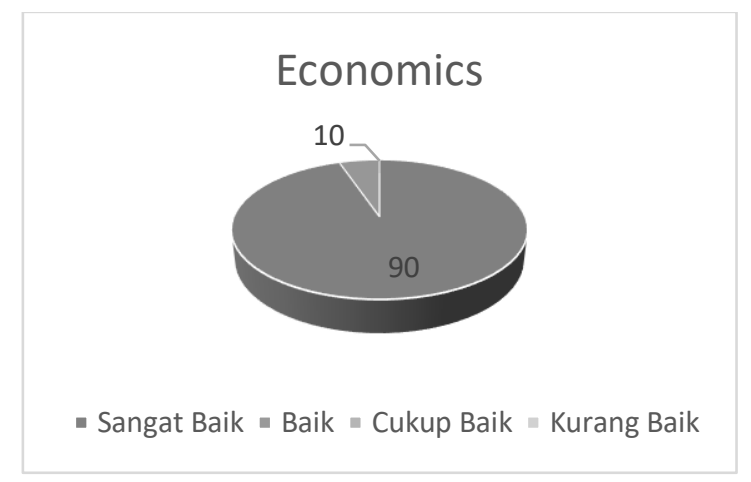

Gambar 4. Ekonomi

Dengan harga produk dengan kisaran Rp.100.00 sampai dengan Rp.150.000, 9 dari 10 orang responden menilai bahwa harga yang ditawarkan cukup terjangkau dengan kinerja perangkat yang baik, perangkat layak untuk diimplementasikan untuk membantu mempraktiskan pengontrollan untuk penghematan daya listrik.

\section{Control and Security}

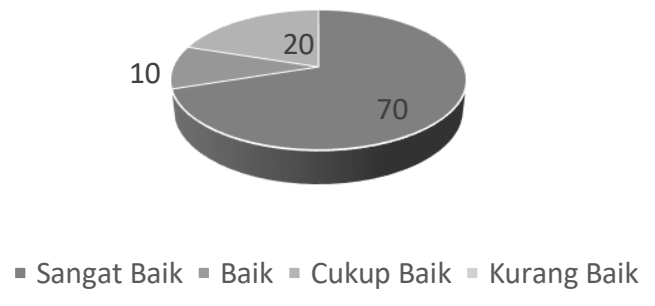

Gambar 5. Control dan Security

Hasil penelitian yang dilakukan, 7 dari 10 orang responden menilai bahwa control dan keamanan dalam menggunakan perangkat Bardi ini sangat baik karena dengan adanya fitur yang tersedia seperti mati dan nyala perangkat dari jarak jauh, responden tidak perlu khawatir jika lupa mematikan perangkat elektronik yang terhubung dengan daya listrik. 1 dari 10 responden menilai control dan keamanan 
Vol. 3, No. 2, June 2021

p-ISSN: 2656-5935 http://journal-isi.org/index.php/isi

e-ISSN: 2656-4882

yang diberikan oleh perangkat sudah cukup baik, tetapi diperlukan jaringan wifi stabil yang terhubung dengan perangkat agar tidak terjadi keterlambatan respon antar perangkat dan aplikasi. Sedangkan 2 orang lainnya menilai bahwa control dan keamanan Bardi cukup baik, hal ini dikarenakan pada saat pengimplementasian perangkat, perangkat bisa digunakan oleh device yang berbeda dengan cara menambatkan perangkat pada google. Responden menilai ini cukup berbahaya karena bisa saja perangkat di retas.

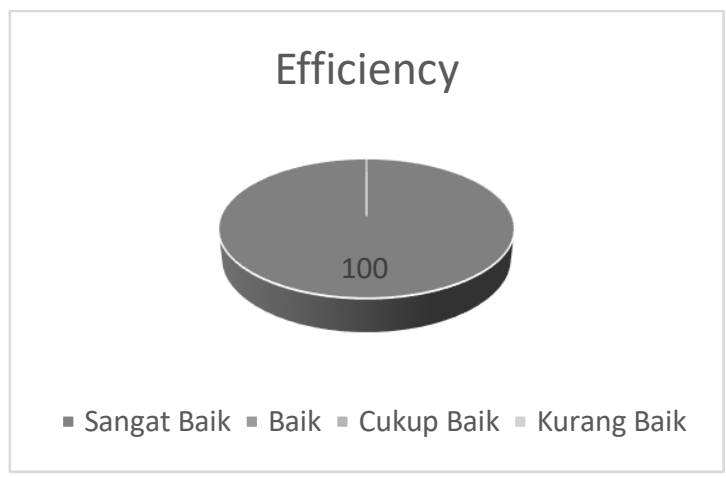

Gambar 6. Efficiency

Efisiensi dari perangkat dinilai semua responden cukup baik karena perangkat sangat membantu responden dalam pengontrollan pemkaian daya listrik yang lebih praktis. Hal ini menurut responden dapat menurunkan tingkat penggunaan listrik dan dapat mengefisiensikan penggunaan listrik sesuai kebutuhan sehari-hari.

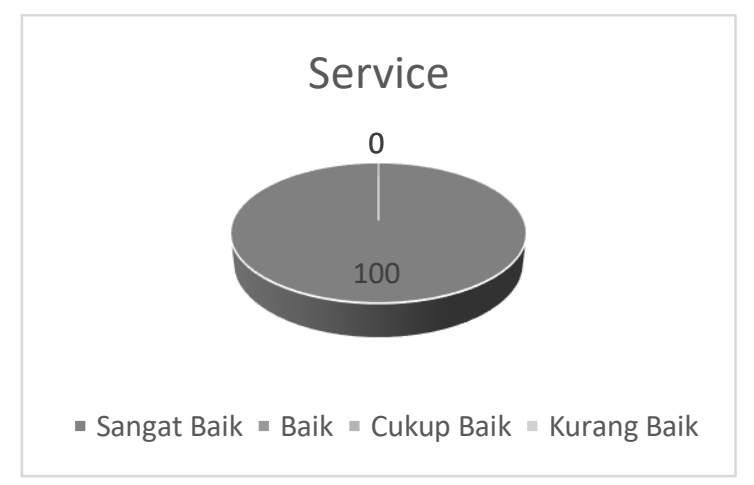

Gambar 7. Services

Layanan yang disediakan oleh Bardi Smart Home untuk membantu menjawab keluhan dan memberikan solusi dinilai 10 orang responden sudah cukup baik karena layanan kinerja perangkat sudah sangat baik. Layanan komunikasi daring yang diberikan juga melalui forum chat antar pengguna dan informasi kontak pada situs bardi sudah sangat baik bila ditemukan suatu kendala atau masalah.

\section{KESIMPULAN}


Berdasarkan hasil analisis dan penelitian yang telah dilakukan kepada 10 orang responden pengguna perangkat dan aplikasi Bardi Smart Home, dapat disimpulkan perangkat berbasis Internet of tersebut sangat membantu pengguna dalam proses pemantauan, pengontrollan, dan penjadwalan penggunaan perangkat atau barang yang membutuhkan aliran listrik untuk manajemen penggunaan daya listrik dalam aktivitas sehari-hari. Dengan harga yang cukup terjangkau dan kinerja yang baik, perangkat Bardi Smart Home layak untuk diterapkan dalam kehidupan sehari-hari. Pemakaian listrik yang awalnya tidak teratur dan boros, dapat teratasi dengan fitur pengontrolan mati dan nyala jarak jauh. Perangkat Bardi dinilai sudah sangat baik untuk efisiensi penggunaan daya listrik. Berdasarkan penelitian yang dilakukan, Sepuluh orang responden puas dengan kinerja perangkat dan aplikasi Bardi Smart Home, karena dinilai sangat praktis digunakan dalam membantu aktivitas dan manajeman penggunaan daya listrik sehari-hari. Pengimplementasian perangkat Bardi Smart Home terbukti dapat meningkatkan efisiensi penggunaan daya listrik sebesar lima belas sampai dengan dua puluh persen dibandingkan tanpa menggunakan perangkat berbasis IoT ini. Hal ini dikarenakan, adanya fitur penjadwalan untuk penggunaan listrik yang teratur, jadi daya listrik akan mati dan nyala secara otomatis sesuai jadwal yang diatur pengguna. Pengguna tidak perlu khawatir jika lupa mematikan perangkat lagi karena adanya fitur ini. Untuk perangkat smart plug, sudah dilengkapi dengan halaman data statistic penggunaan listrik. Tetapi untuk perangkat smart lamp tidak ada data statistik penggunaan listrik. Diharapkan versi selanjutnya, perangkat smart lamp sudah menampilkan data statistik seperti yang terdapat pada smart plug penggunaan listrik. Agar lebih membantu management pemakaian listrik pengguna.

\section{DAFTAR PUSTAKA}

[1] Lidwina, Andrea. (2020) Konsumsi Listrik Nasional Terus Meningkat. Available at: https://databoks.katadata.co.id/ (Accessed: 20 January 2021)

[2] Pranadhitya. (2019). Pengertian Internet of Things (IoT). Available at: https://pranadhityaa-ti-poltektegal.blogspot.com/ (Accessed: 4 February 2021)

[3] L, W., Jeffrey and Bentley, L. D. (2007) System Analysis \& Design Methods Seventh Edition. Edisi 7. New York, USA: McGraw-Hill.

[4] Sakti, E. M. S. (2015) Jaringan nir kabel. Modul Perk. Universitas Persada Indonesia

[5] Sas (2021) Big Data, sas.com. Available at: https://www.sas.com/id_id/insight/big-data/what-is-big-data.html (Accessed: 5 February 2021) 